\title{
Fabrication of ZnO "Dandelions" via a Modified Kirkendall Process
}

Bin Liu and Hua Chun Zeng*

Department of Chemical and Biomolecular Engineering, Faculty of Engineering

National University of Singapore, 10 Kent Ridge Crescent, Singapore 119260

\section{SI-1 Ball-like morphology of as-received Zn powder (SEM images)}

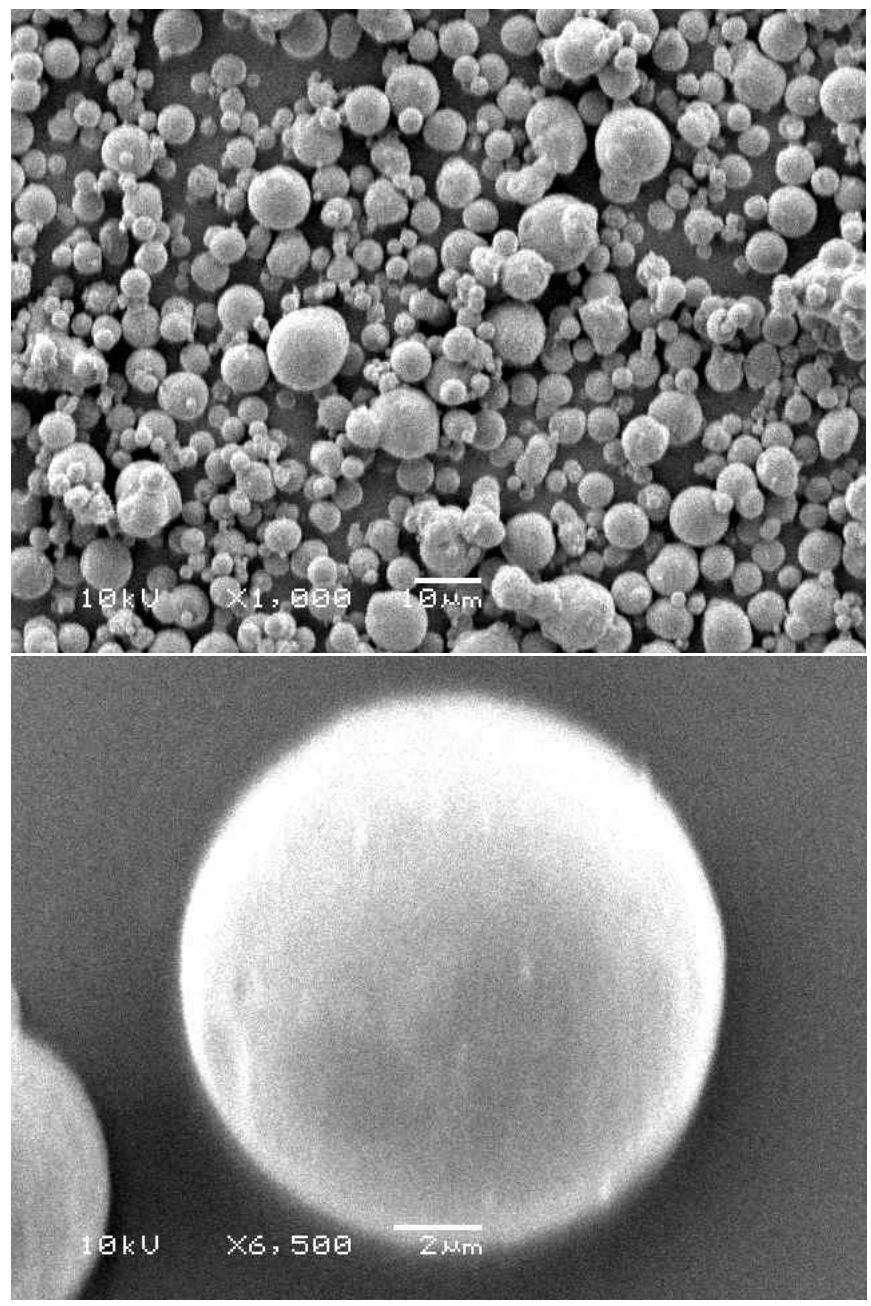

Note: The above two images were taken with a scanning electron microscope (SEM, JSM-5600LV). 


\section{SI-2 EDX result for $\mathrm{ZnO}$ dandelions}

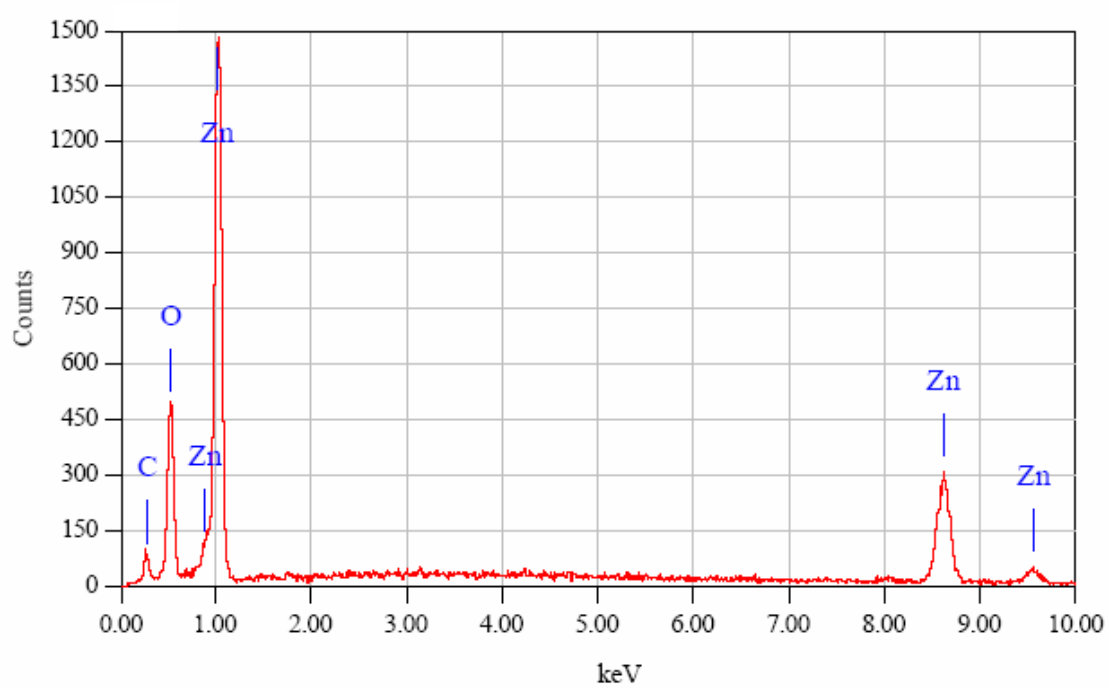

Notes: 1) Atomic ratio of $\mathrm{Zn}: \mathrm{O}=49.6: 50.4$.

2) The carbon signal comes from the carbon-coated double-sided tape.

\section{SI-3 $100 \%$ yield of ZnO dandelions (SEM images)}

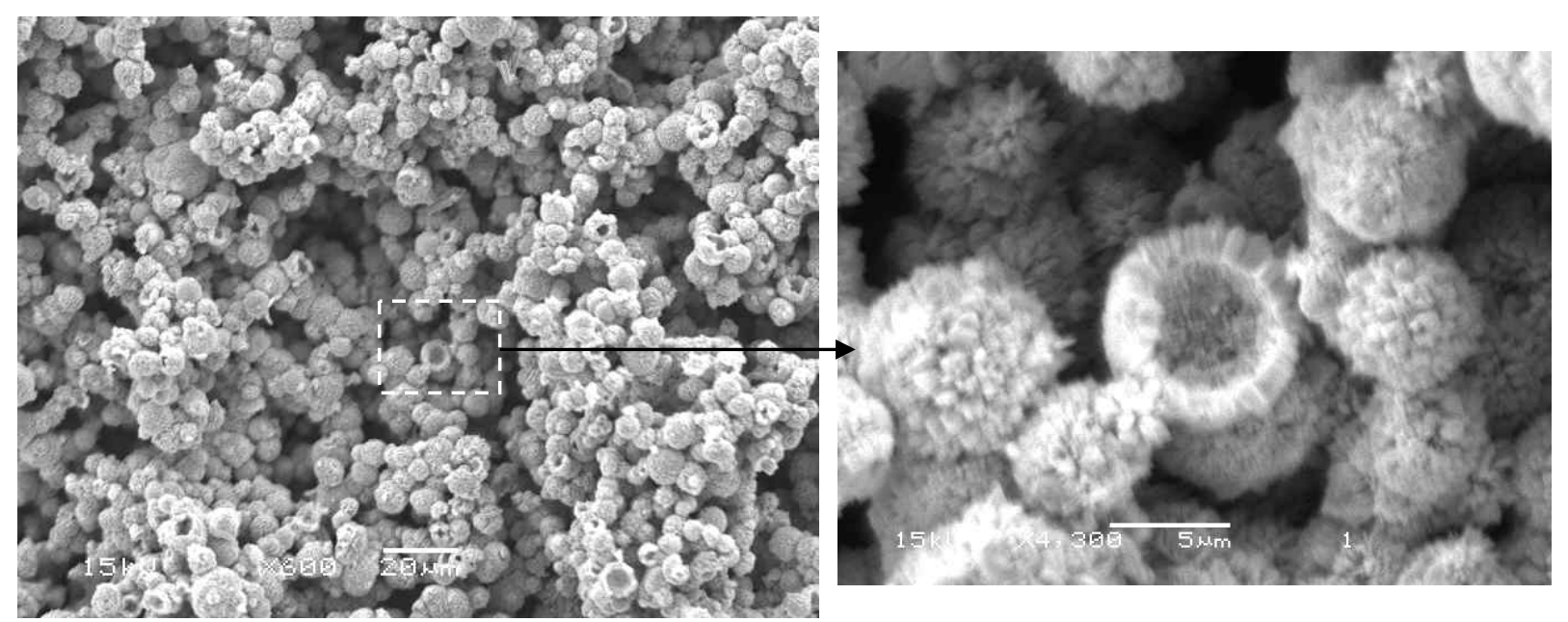

Notes: 1) Experimental conditions: $0.65 \mathrm{~g}$ of zinc powder was added to $25 \mathrm{~mL}$ of DI water, followed by adding $5 \mathrm{~mL}$ of zincate ion solution (see the main text). The mixture was then transferred to a Teflon-lined autoclave and kept in an electric oven at $150{ }^{\circ} \mathrm{C}$ for $24 \mathrm{~h}$.

2) Hollow interiors of the dandelions can be easily observed in some cracked spheres.

3) The above images were taken with a scanning electron microscope (SEM, JSM-5600LV). 


\section{SI-4 ZnO dandelions synthesized from small-sized Zn balls (FESEM images)}
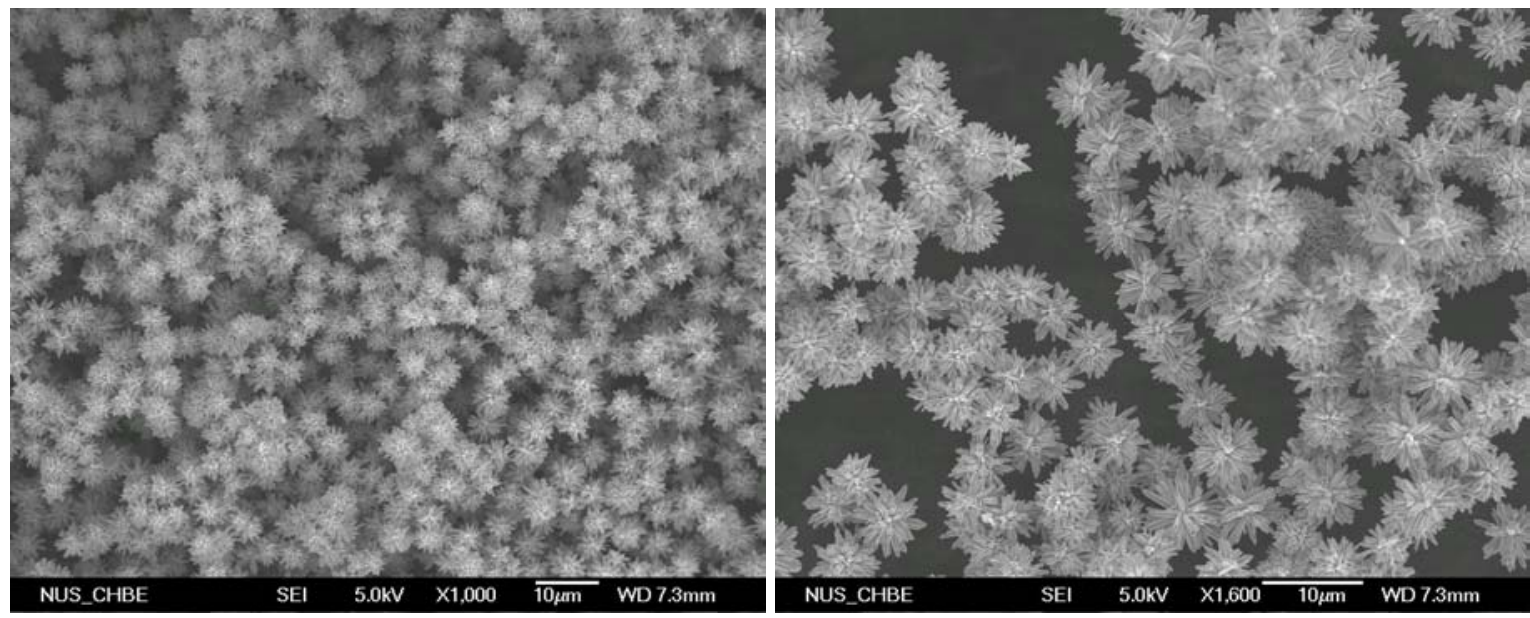

Notes: 1) Experimental conditions: $0.65 \mathrm{~g}$ of zinc powder was added to $25 \mathrm{~mL}$ of DI water, followed by adding $5 \mathrm{~mL}$ of zincate ion solution (see the main text). The mixture was then transferred to a Teflon-lined autoclave and kept in an electric oven at $180^{\circ} \mathrm{C}$ for $2 \mathrm{~h}$.

2) High morphological yield is achieved via a simple sedimentation separation (one-run only).

\section{SI-5 ZnO dandelions with nanoplatelets (FESEM image)}

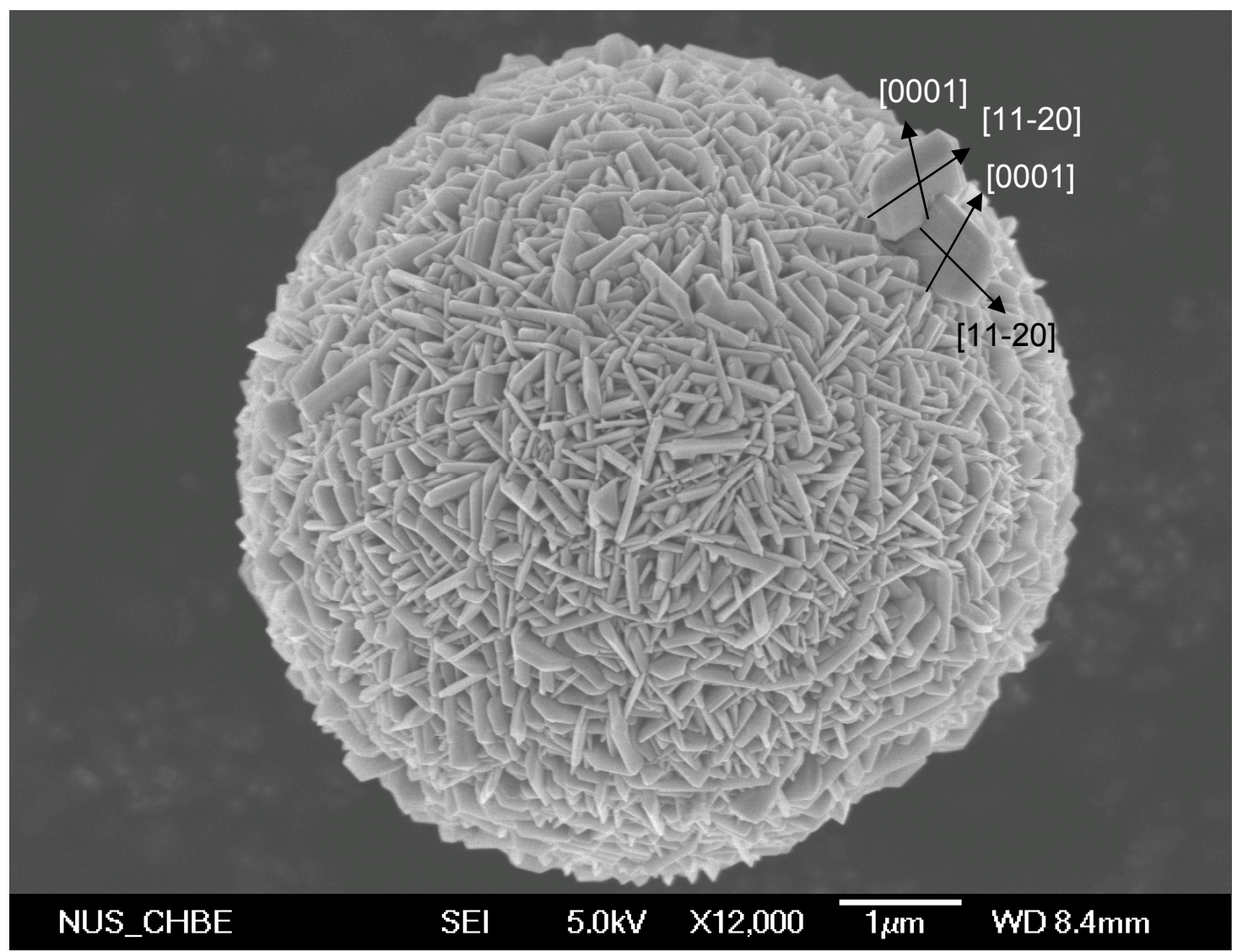

Notes: 1) Experimental conditions: $0.65 \mathrm{~g}$ of zinc powder was added to $25 \mathrm{~mL}$ of DI water, followed by adding $5 \mathrm{~mL}$ of zincate ion solution (see the main text). The mixture was then transferred to a Teflon-lined autoclave and kept in an electric oven at $200{ }^{\circ} \mathrm{C}$ for $4 \mathrm{~h}$.

2) The crystal orientations of two large $\mathrm{ZnO}$ platelets landed on the sphere are illustrated. 

range of 150-200 $\mathrm{nm}$ (FESEM images)
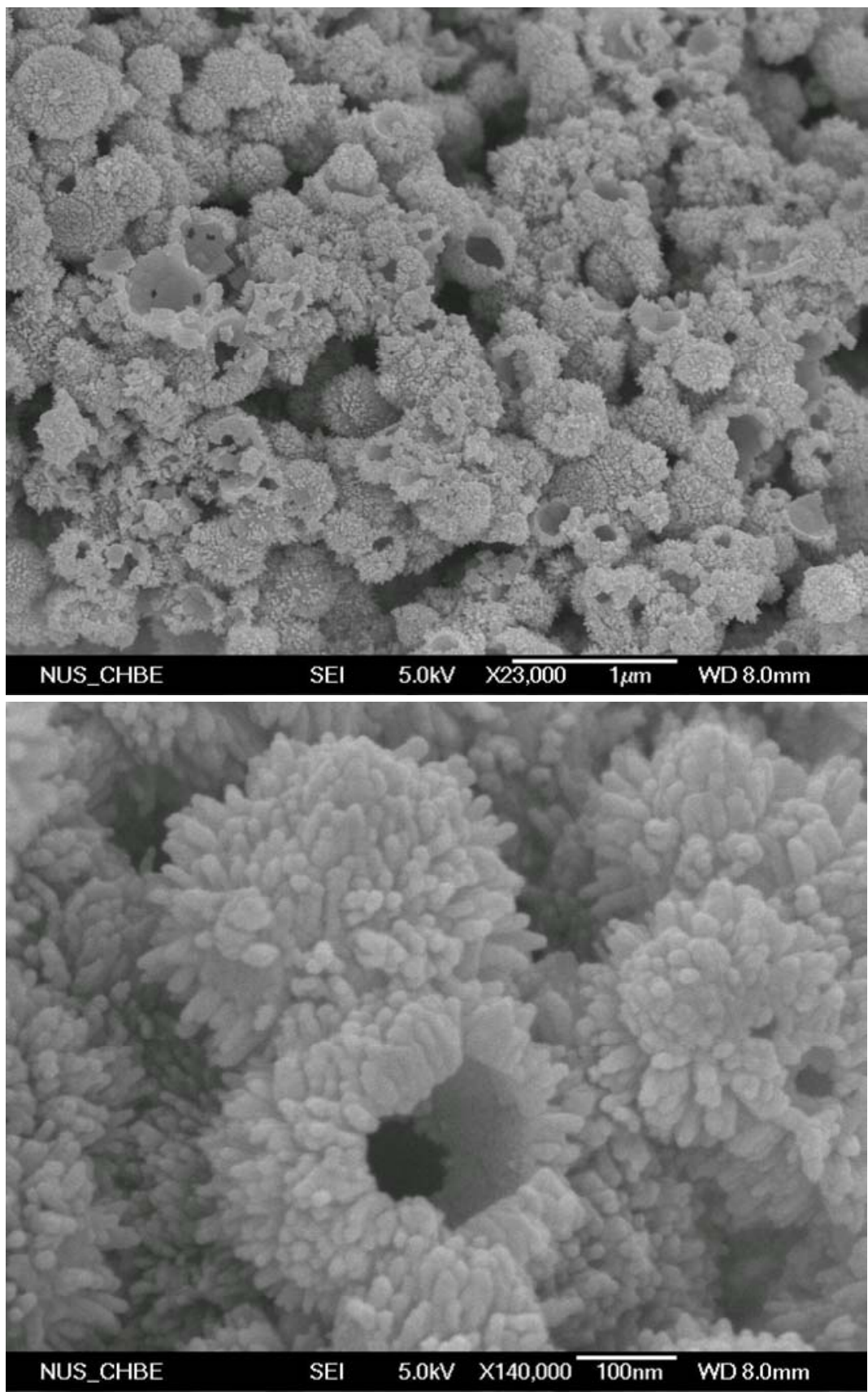

Notes: 1) The above two FESEM images show the interior space of small $\mathrm{ZnO}$ dandelions (around $300 \mathrm{~nm}$ ) from cracked samples.

2) Experimental conditions: $0.65 \mathrm{~g}$ of zinc powder was added to $25 \mathrm{~mL}$ of DI water, followed by adding $5 \mathrm{~mL}$ of zincate ion solution (see the main text). The mixture was kept at $25^{\circ} \mathrm{C}$ for $4 \mathrm{~h}$. 


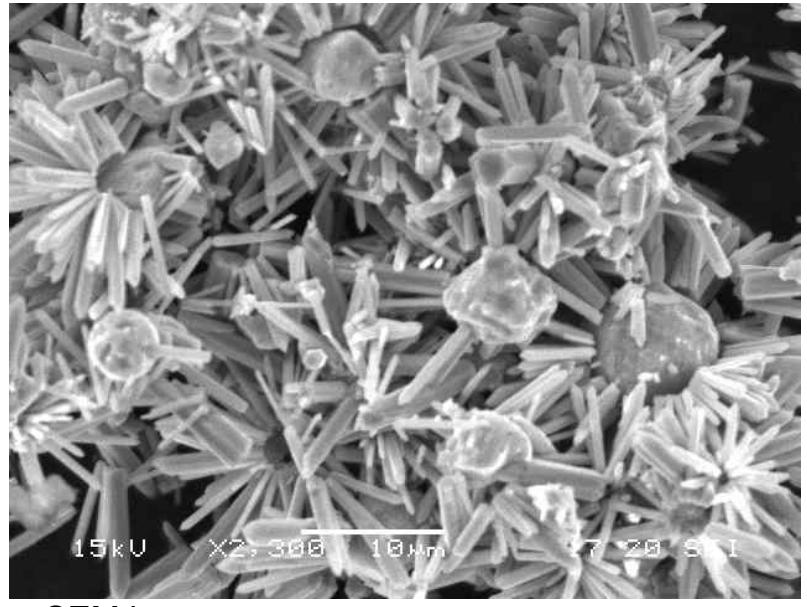

SEM image

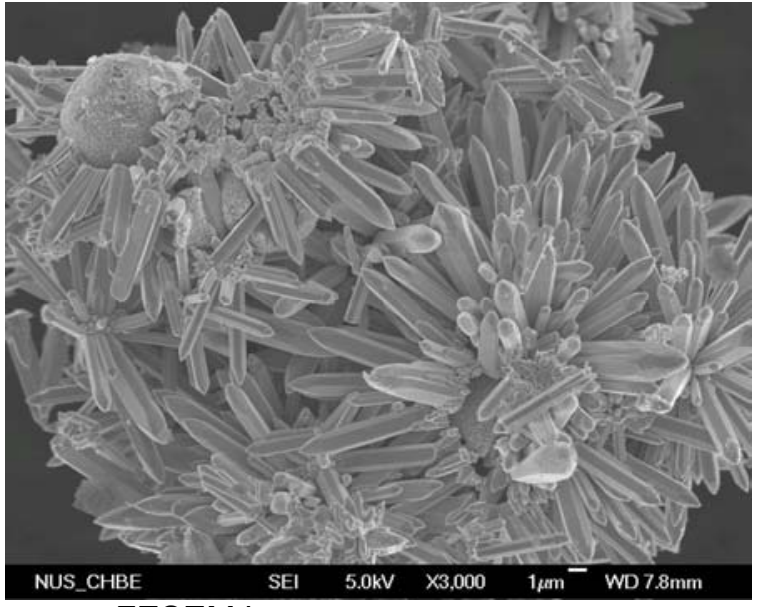

FESEM image

Without using initial zincate ion solution in synthesis:

Notes: 1) Due to the dissolution of pristine $\mathrm{ZnO}$ surface layer, only incomplete dandelions can be formed.

2) Experimental conditions: $0.65 \mathrm{~g}$ of zinc powder was added to $25 \mathrm{~mL}$ of DI water, followed by adding $5 \mathrm{~mL}$ of $5 \mathrm{M} \mathrm{NaOH}$. The mixture was then transferred to a Teflon-lined autoclave and kept in an electric oven at $180{ }^{\circ} \mathrm{C}$ for $2 \mathrm{~h}$.

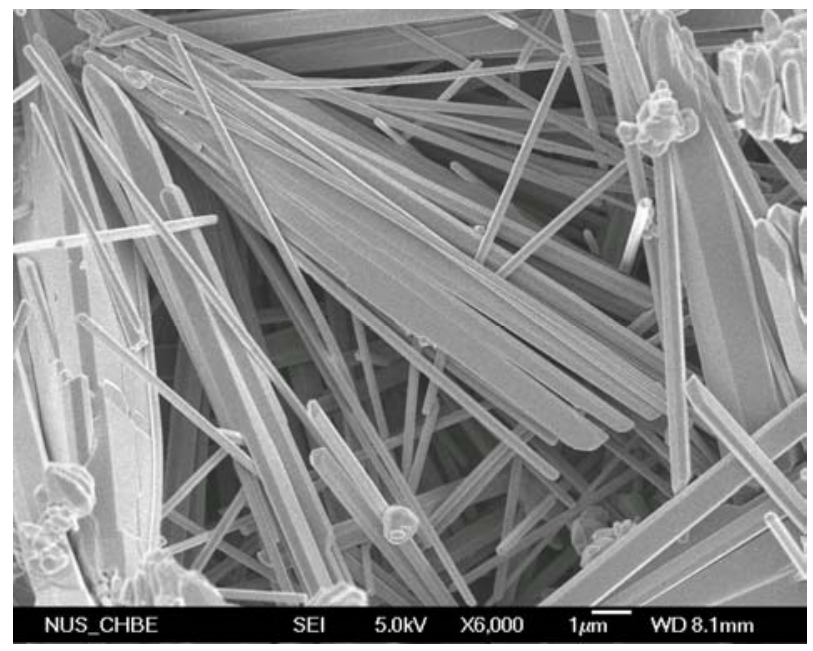

FESEM image

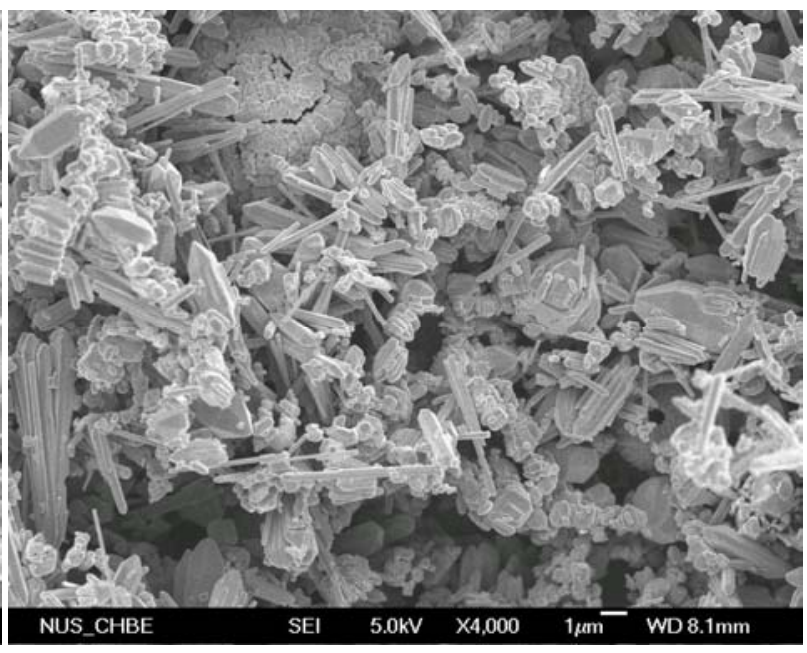

FESEM image

With high-concentration of initial zincate ion in synthesis

Notes: 1) Due to a high-concentration of initial zincate ions used in synthesis, spontaneous nucleation occurs in solution phase, giving away unorganized $\mathrm{ZnO}$ products.

2) Experimental conditions: $0.65 \mathrm{~g}$ of zinc powder was added to $30 \mathrm{~mL}$ of zincate ion solution (see the main text). The mixture was then transferred to a Teflon-lined autoclave and kept in an electric oven at $150{ }^{\circ} \mathrm{C}$ for $24 \mathrm{~h}$. 
SI-8 Zn@ZnO yolk-shell structure (FESEM images, see Figure 1(ii))
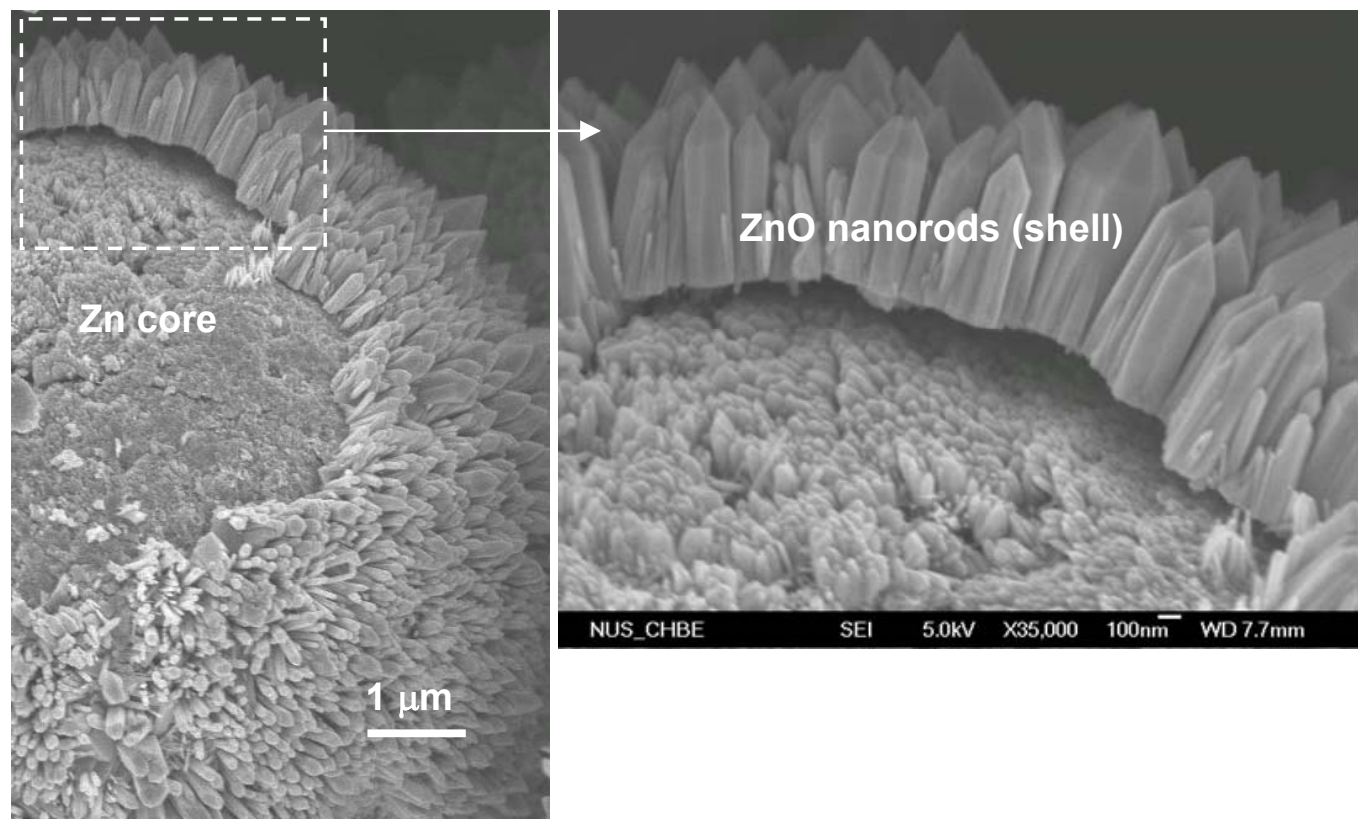

Note: Experimental conditions: $0.65 \mathrm{~g}$ of zinc powder was added to $25 \mathrm{~mL}$ of DI water, followed by adding 5 $\mathrm{ml}$ of zincate ion solution (see the main text, Figure 1(ii)). Then the mixture was transferred to a Teflonlined autoclave and kept in an electric oven at $180{ }^{\circ} \mathrm{C}$ for $2 \mathrm{~h}$. 


\section{SI-9 Element-mappings of $\mathrm{Zn}, \mathrm{O}$, and $\mathrm{Au}$ in $\mathrm{Au}-\mathrm{ZnO}$ composite dandelions}
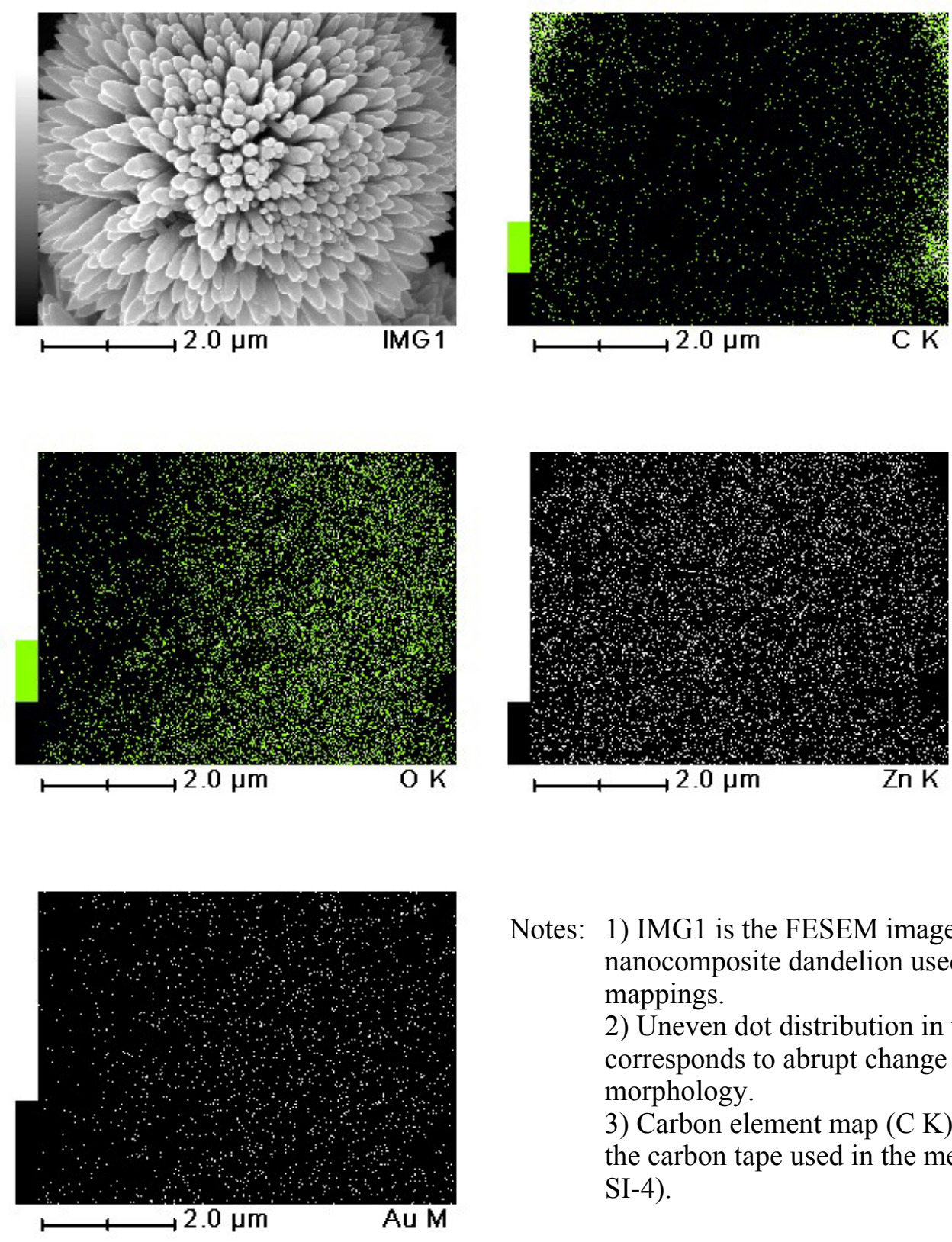

Notes: 1) IMG1 is the FESEM image of an $\mathrm{Au}-\mathrm{ZnO}$ nanocomposite dandelion used in the EDX element mappings.

2) Uneven dot distribution in the mappings corresponds to abrupt change in crystal morphology.

3) Carbon element map ( $\mathrm{C} \mathrm{K}$ ) detected is due to the carbon tape used in the measurement (also see SI-4).

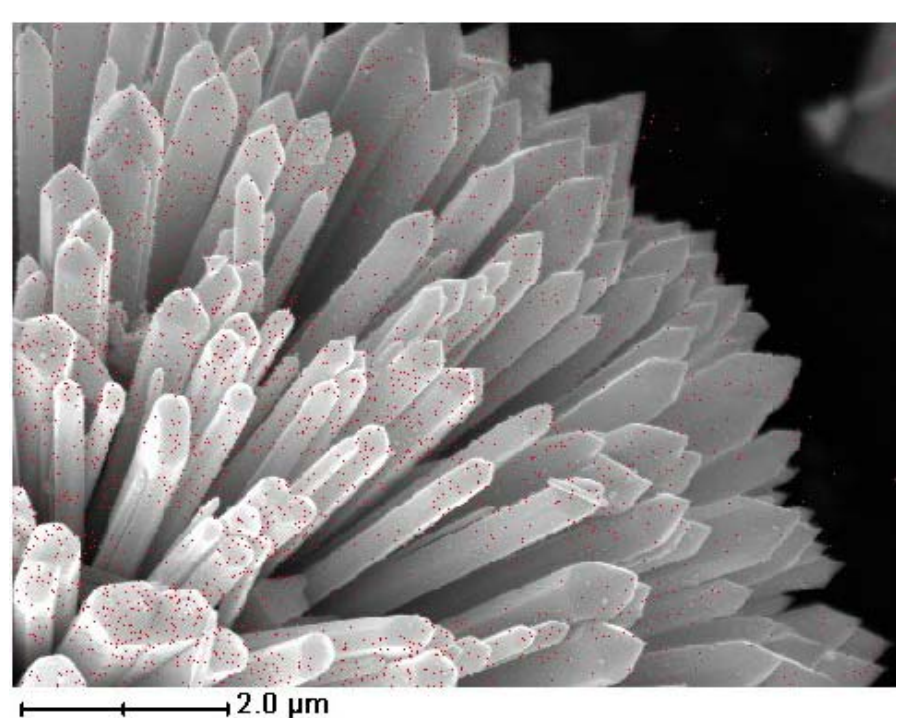

Note: A detailed view on Figure 7C in the main text $(N B$ : This dandelion is different from IMG1 above). 


\section{SI-10 FESEM images of deposited Au nanospheres}

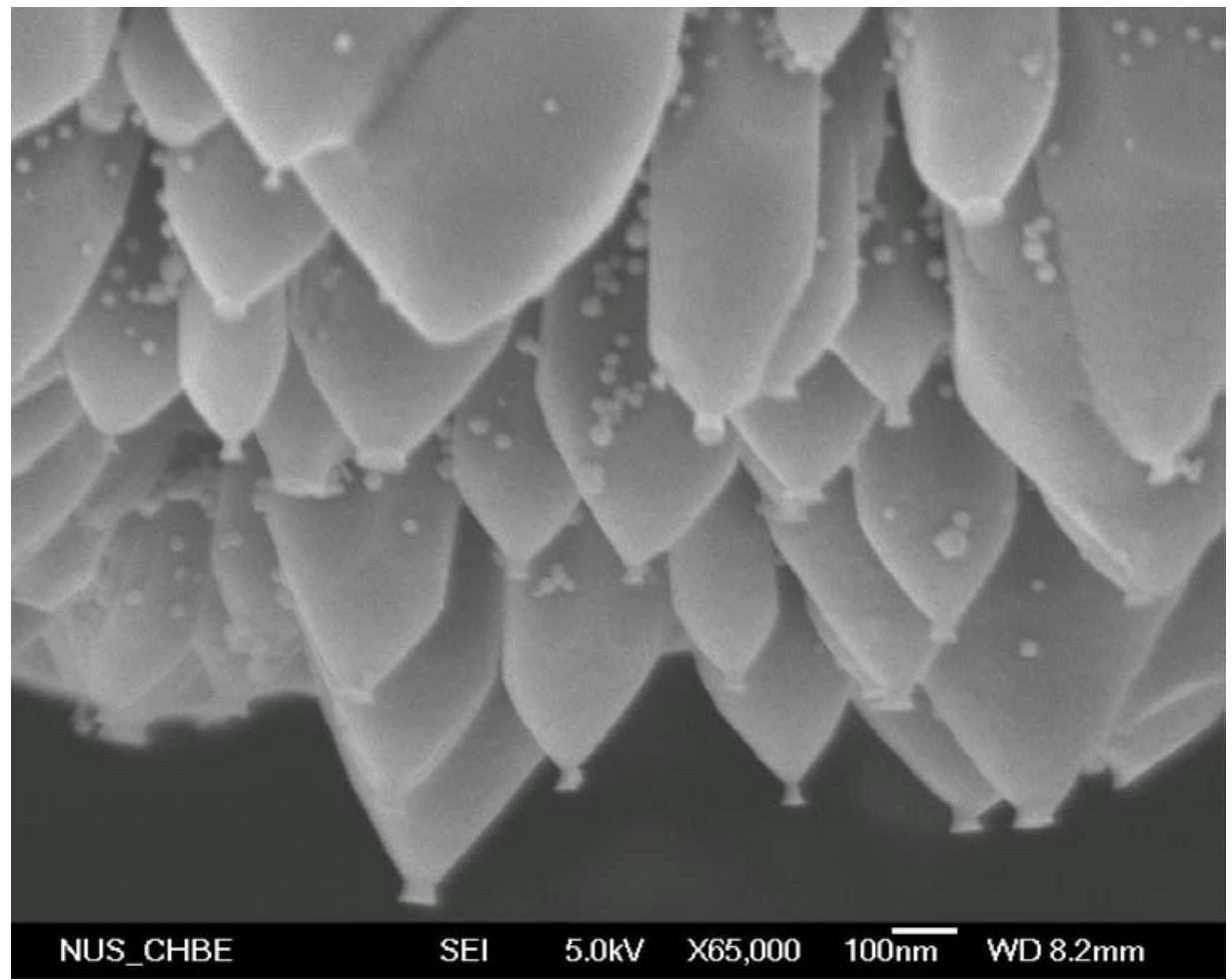

Notes: 1) Original $\mathrm{ZnO}$ dandelions remain intact after $\mathrm{Au}$ deposition.

2) Each tip (i.e., on (0002) plane) of $\mathrm{ZnO}$ nanorod is decorated with an Au particle in addition to those on the six prismatic crystal planes (see the following image).

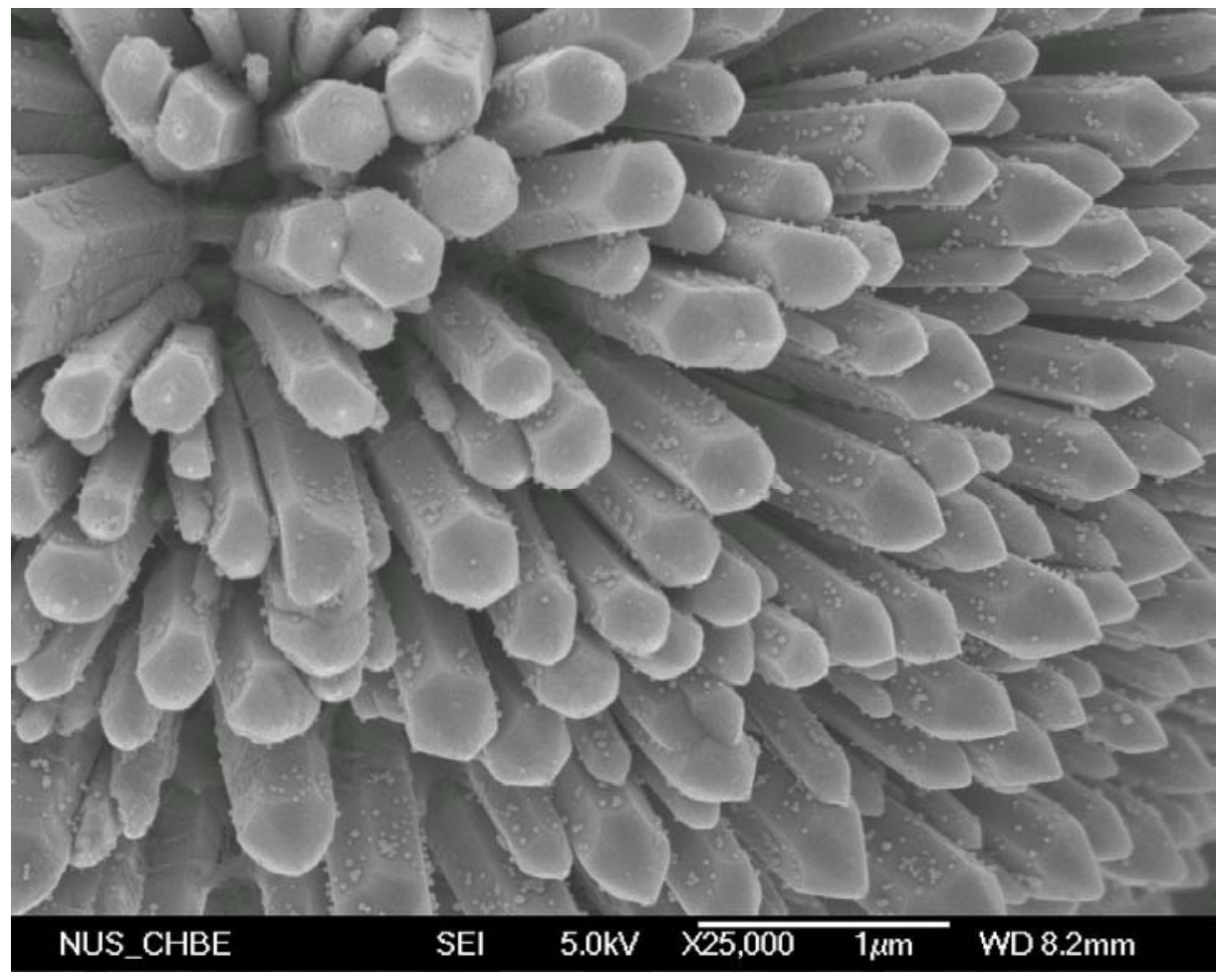

Notes: 1) A detailed view on Au nanoparticles on the six prismatic planes of $\mathrm{ZnO}$ nanorods.

2) Au nanoparticles on the tips are less clear due to a near perpendicular view. 